Original Research Article

\title{
A comparative study of metabolic side effects of risperidone and olanzapine in the treatment of schizophrenia
}

\author{
Lavanya Nagaraj $^{1}$, Naveen Kumar Madalageri ${ }^{2}$ *
}

${ }^{1}$ Department of Pharmacology, Sree Narayana Institute of Medical Science, Chalakka, Ernakulam, Kerala, India ${ }^{2}$ Department of Pharmacology, Al Azhar Medical College and Super speciality hospital, Ezhalloor, Thodupuzha, Kerala, India

Received: 01 October 2019

Revised: 16 October 2019

Accepted: 17 October 2019

\section{*Correspondence to:}

Dr. Naveen Kumar Madalageri, Email: dr.naveen.madalageri@ gmail.com

Copyright: (C) the author(s), publisher and licensee Medip Academy. This is an openaccess article distributed under the terms of the Creative Commons Attribution NonCommercial License, which permits unrestricted noncommercial use, distribution, and reproduction in any medium, provided the original work is properly cited.

\begin{abstract}
Background: Schizophrenia is one of most serious chronic psychiatric disorder, which affects about $1 \%$ of population. Treatment of schizophrenia comprises of typical antipsychotics and or atypical antipsychotics. Typical antipsychotics like haloperidol have extrapyramidal side effects which limit their use in chronic cases. Atypical antipsychotics though have better treatment response, they have metabolic side effects like hypercholesteremia, hypertriglyceridemia and hyperglycaemia. As there is paucity of data in Indian population the present study has been taken up to compare the metabolic side effects of risperidone and olanzapine in the treatment of schizophrenic patients in a tertiary care hospital.

Methods: It was a comparative study conducted on 60 patients of Schizophrenia for one year in a tertiary care hospital. The study subjects were randomly assigned into 2 groups of 30 patients each, where group 1 were treated with atypical antipsychotic drug risperidone and group 2 with Olanzapine and both groups received the treatment for one year. Metabolic side effects like hypercholesteremia, hypertriglyceridemia and hyperglycaemia were evaluated and compared over a period of one year.

Results: Both risperidone and olanzapine were associated with comparable baseline to endpoint increase in metabolic side effects. However, risperidone treated subjects had significantly less metabolic side effects compared to olanzapine.

Conclusions: Apart from total cholesterol and triglycerides, other metabolic side effects were less in risperidone treated patients than olanzapine treated patients.
\end{abstract}

Keywords: Risperidone, Olanzapine, Atypical antipsychotics, Metabolic side effects

\section{INTRODUCTION}

Schizophrenia is one of most serious chronic psychiatric disorder, which affects about $1 \%$ of population. Treatment of schizophrenia begun in 1950s with typical antipsychotics. Due to partial to the treatment and extrapyramidal side effects of typical antipsychotics, newer atypical antipsychotics were introduced which have better treatment response and fewer extrapyramidal side effects. ${ }^{1}$ But these atypical antipsychotics like olanzapine and risperidone have shown metabolic side effects like hypercholesteremia, hypertriglyceridemia and hyperglycaemia. ${ }^{1,2}$

Atypical antipsychotics like risperidone and olanzapine have associated with metabolic side effects when used for more than 12 weeks in the treatment of schizophrenia. ${ }^{3}$

Studies done on metabolic side effects of risperidone and olanzapine showed that, olanzapine has greater increase in fasting blood glucose and lipid profile than risperidone treated patients. But there is no significant difference in terms of weight gain in both groups. ${ }^{4}$ 
As there is paucity of data in Indian population the present study has been taken up to compare the metabolic side effects of risperidone and olanzapine in the treatment of schizophrenic patients in a tertiary care hospital.

\section{METHODS}

Patient data was collected from outpatients and inpatients in the department of psychiatry, Victoria hospital, Bangalore. It was a prospective observational study conducted from January 2010 to June 2011. After obtaining approval and clearance from the institution ethical committee, 60 patients with schizophrenia who gave written informed consent were included for the study. The study subjects fulfilling the inclusion or exclusion criteria were randomly assigned into 2 groups of 30 patients in each group. Group 1: Patients treated with risperidone (oral dose $2 \mathrm{mg}$ /day). Group 2: Patients treated with olanzapine (oral dose $2.5 \mathrm{mg}$ to $20 \mathrm{mg}$, Mean dose $7 \mathrm{mg} /$ day)

\section{Inclusion criteria}

Inclusion criteria were patients of either sex aged between 18-65 years suffering from schizophrenia; patients who fulfilled the criteria of ICD-10 (International Classification of Disease-10, WHO1992); patients in the respective groups who were on treatment with that particular drug for a minimum duration of 3 months; patients who gave written informed consent.

\section{Exclusion criteria}

Exclusion criteria were patients who received more than one antipsychotic medication and who had received them in the past one year; patient with major psychiatric illness; patients with co-morbid medical conditions like diabetes mellitus, dyslipidaemia, coronary heart disease, hypertension, Parkinson disease; patient with concomitant physical illness; presence of alcohol and substance abuse/dependence, epilepsy, mental retardation, mental disorders other than schizophrenia; patient suffering from any major endocrine disorders; pregnant and lactating women; non-compliant patients who were unable to give consent for the study.

In first visit i.e. day one, patients were informed fully about the purpose and requirements of the study and written informed consent has been obtained. Details of patient's medical history, concomitant medication, pill count and detailed physical/psychiatric evaluation were recorded. Blood samples for relevant baseline laboratory investigations were collected. Blood investigations like fasting blood glucose, total cholesterol, triglycerides, high density lipoprotein (HDL) and low-density lipoprotein (LDL) were done. Patient's weight, body mass index (BMI) and waist hip ration were recorded. Body mass index was measured using Quetelet's body mass index formula. ${ }^{5}$ These parameters are taken as a baseline data.
Concomitant use of anticholinergics, selective serotonin reuptake inhibitors, benzodiazepines and electroconvulsive therapy are permitted as and when needed. Patients were issued medication once every month and instructed for regular follow up there after. Patients were clinically assessed once in 3 months. During subsequent visits i.e. visit 2 ( $3^{\text {rd }}$ month), visit 3 $\left(6^{\text {th }}\right.$ month), visit 4 ( $9^{\text {th }}$ month) and visit 5 (1 year) medication compliance, pill count, any intercurrent illness or change in concomitant medications were recorded. Relevant blood investigations were done at $3^{\text {rd }}$ visit (6 months) and $5^{\text {th }}$ visit (one year). A thorough physical/ psychiatric evaluation was carried out and recorded in each visit. If any adverse event is persistent or there is any abnormal laboratory value of clinical significance appropriate follow up was made and patients were advised about further therapy

\section{Statistical methods}

Descriptive statistical analysis has been carried out in the present study. Results on continuous measurements are presented on Mean \pm SD (Min-Max) and results on categorical measurements are presented in Number $(\%)$. Significance is assessed at $5 \%$ level of significance.

It was assumed that dependent variables were normally distributed. It was also assumed that samples drawn from the population were random, and cases of the samples were independent.

\section{RESULTS}

Table 1 shows weight changes among the study subjects. In group I (risperidone) there was mean increase in the weight from baseline $59.70 \pm 5.27$ to last follow up $62.37 \pm 6.01$ with mean difference of $2.67 \pm 2.63$. In group II (Olanzapine) there was mean increase in the weight from baseline $59.60 \pm 4.74$ to last follow up $63.93 \pm 6.95$ with mean difference of $4.33 \pm 2.93$. There was statistically significant $(\mathrm{p}<0.001)$ increase in body weight from baseline to last follow up in both groups.

Table 1: Weight changes among the study subjects.

\begin{tabular}{|lll|}
\hline Weight (kg) & $\begin{array}{l}\text { Group I } \\
\text { (risperidone) }\end{array}$ & $\begin{array}{l}\text { Group II } \\
\text { (olanzapine) }\end{array}$ \\
\hline Pre-treatment & $59.70 \pm 5.27$ & $59.60 \pm 4.74$ \\
\hline Post treatment & $62.37 \pm 6.01$ & $63.93 \pm 6.95$ \\
\hline Mean difference & $2.67 \pm 2.63$ & $4.33 \pm 2.93$ \\
\hline P value & $<0.001 * *$ & $<0.001 * *$ \\
\hline$* *$ p $<0.001$. & & \\
\hline
\end{tabular}

Table 2 shows changes in the BMI among the study subjects. In group I (risperidone) there was mean increase in the BMI from baseline $22.02 \pm 0.81$ to last follow up $22.99 \pm 1.64$ with mean difference of $0.98 \pm 1.06$. In group II (olanzapine) there was mean increase in the BMI from baseline $21.01 \pm 1.89$ to last follow up $22.46 \pm 2.77$ with mean difference of $1.44 \pm 1.07$. There was statistically 
significant $(\mathrm{p}<0.001)$ increase in BMI from baseline to last follow up in both groups.

Table 2: Change in the BMI among the study subjects.

\begin{tabular}{|lll|}
\hline BMI $\left(\mathrm{kg} / \mathrm{m}^{2}\right)$ & $\begin{array}{l}\text { Group I } \\
\text { (risperidone) }\end{array}$ & $\begin{array}{l}\text { Group II } \\
\text { (olanzapine) }\end{array}$ \\
\hline Pre-treatment & $22.02 \pm 0.81$ & $21.01 \pm 1.89$ \\
\hline Post treatment & $22.99 \pm 1.64$ & $22.46 \pm 2.77$ \\
\hline Mean difference & $0.98 \pm 1.06$ & $1.44 \pm 1.07$ \\
\hline P value & $<0.001 * *$ & $<0.001 * *$ \\
\hline
\end{tabular}

Table 3: Change in the waist hip ratio among the study subjects.

\begin{tabular}{|lll|}
\hline Waist-hip ratio & $\begin{array}{l}\text { Group I } \\
\text { (risperidone) }\end{array}$ & $\begin{array}{l}\text { Group II } \\
\text { (olanzapine) }\end{array}$ \\
\hline Pre-treatment & $0.815 \pm 0.03$ & $0.819 \pm 0.031$ \\
\hline Post treatment & $0.833 \pm 0.040$ & $0.846 \pm 0.040$ \\
\hline Mean difference & $0.019 \pm 0.02$ & $0.026 \pm 0.022$ \\
\hline P value & $<0.001 * *$ & $<0.001 * *$ \\
\hline$* * \mathrm{p}<0.001$ & & \\
\hline
\end{tabular}

Table 3 shows changes in the waist hip ratio among the study subjects. In group I (risperidone) there was mean increase in the waist hip ratio from baseline $0.815 \pm 0.03$ to last follow up $0.833 \pm 0.040$ with mean difference of $0.019 \pm 0.02$. In group II (olanzapine) there was mean increase in the waist hip ratio from baseline $0.819 \pm 0.031$ to last follow up $0.846 \pm 0.040$ with mean difference of $0.026 \pm 0.022$. There was statistically significant $(\mathrm{p}<0.001)$ increase in waist hip ratio from baseline to last follow up in both groups.

Table 4: Changes in the lipid profile of study subjects.

\begin{tabular}{|llll|}
\hline $\begin{array}{l}\text { Lipid } \\
\text { parameters }\end{array}$ & $\begin{array}{l}\text { Group I } \\
\text { (risperidone) }\end{array}$ & $\begin{array}{l}\text { Group II } \\
\text { (olanzapine) }\end{array}$ & P value \\
\hline \multicolumn{4}{|l|}{ Total cholesterol } \\
\hline Visit 1 & $138.47 \pm 17.59$ & $175.13 \pm 48.14$ & $<0.001^{* *}$ \\
\hline Visit 3 & $151.97 \pm 24.60$ & $180.30 \pm 52.68$ & $0.005^{* *}$ \\
\hline Visit 5 & $165.70 \pm 31.41$ & $183.83 \pm 55.36$ & 0.146 \\
\hline Triglyceride & & & \\
\hline Visit 1 & $96.20 \pm 24.11$ & $107.37 \pm 18.20$ & $0.066+$ \\
\hline Visit 3 & $99.73 \pm 27.26$ & $111.00 \pm 20.32$ & 0.117 \\
\hline Visit 5 & $110.47 \pm 35.13$ & $111.30 \pm 20.40$ & 0.990 \\
\hline HDL & & & \\
\hline Visit 1 & $40.30 \pm 3.36$ & $45.13 \pm 6.30$ & $0.001^{* *}$ \\
\hline Visit 3 & $38.97 \pm 2.97$ & $44.20 \pm 6.69$ & $0.001^{* *}$ \\
\hline Visit 5 & $37.60 \pm 3.81$ & $43.53 \pm 6.94$ & $<0.001^{* *}$ \\
\hline LDL & & & \\
\hline Visit 1 & $78.50 \pm 16.54$ & $98.93 \pm 19.30$ & $<0.001^{* *}$ \\
\hline Visit 3 & $89.03 \pm 18.64$ & $102.77 \pm 22.10$ & $0.008^{* *}$ \\
\hline Visit 5 & $95.77 \pm 28.22$ & $104.17 \pm 24.04$ & $<0.001^{* *}$ \\
\hline$* *$ p $<0.001$. & & & \\
\hline
\end{tabular}

Table 4 shows the changes in lipid profile among study subjects. In group-I (risperidone) there was mean increase in total cholesterol from baseline $138.47 \pm 17.59$ to first follow up $151.97 \pm 24.60$ and in subsequent follow up it was increased to $165.70 \pm 31.41$. In group-II (olanzapine) there was mean increase in total cholesterol from baseline $175.13 \pm 48.14$ to first follow up $180.30 \pm 52.68$ and in subsequent follow up it was increased to $183.83 \pm 55.36$. Though there was statistically significant increase in total cholesterol in both groups on $1^{\text {st }}$ and $3^{\text {rd }}$ visit, change in total cholesterol in group-II (olanzapine) was not significant on $5^{\text {th }}$ visit i.e. at one year.

In group-I (risperidone) there was mean increase in triglyceride level from baseline $96.20 \pm 24.11$ to first follow up $99.73 \pm 27.26$ and in subsequent follow up it was increased to $110.47 \pm 35.13$. In group-II (olanzapine) there was mean increase in triglyceride level from baseline $107.37 \pm 18.20$ to first follow up $111.00 \pm 20.32$ and in subsequent follow up it was increased to $111.30 \pm 20.40$. There was statistically significant increase in triglyceride level from baseline to last follow up in both groups, but it was not significant when compared among both groups.

In group-I (risperidone) there was reduction in HDL level from baseline $40.30 \pm 3.36$ to first follow up $38.97 \pm 2.97$ and in subsequent follow up it was increased to $37.60 \pm 3.81$. In group-II (olanzapine) there was reduction in HDL level from baseline $45.13 \pm 6.30$ to first follow up and in $44.20 \pm 6.69$ subsequent follow up it was increased to $43.53 \pm 6.94$. There was statistically significant reduction in HDL level from baseline to last follow up in both groups and it was significant when compared with each group.

In group-I (risperidone) there was mean increase in LDL level from baseline $78.50 \pm 16.54$ to first follow up $89.03 \pm 18.64$ and in subsequent follow up it was increased to $95.77 \pm 28.22$. In group-II (olanzapine) there was reduction in LDL level from baseline $98.93 \pm 19.30$ to first follow up $102.77 \pm 22.10$ and in subsequent follow up it was increased to $104.17 \pm 24.04$. There was statistically significant increase in LDL level from baseline to last follow up in both groups and it was significant when compared with each group.

Table 5: Changes in fasting blood glucose levels in study subjects.

\begin{tabular}{|llll|}
\hline $\begin{array}{l}\text { FBS } \\
\text { (mg/dl) }\end{array}$ & $\begin{array}{l}\text { Group I } \\
\text { (risperidone) }\end{array}$ & $\begin{array}{l}\text { Group II } \\
\text { (olanzapine) }\end{array}$ & P value \\
\hline $\begin{array}{l}\text { Visit 1 } \\
\text { (baseline) }\end{array}$ & $97.7 \pm 16.81$ & $97.9 \pm 18.45$ & 0.999 \\
\hline $\begin{array}{l}\text { Visit 3 } \\
\text { (6 }\end{array}$ & $105.27 \pm 20.54$ & $114.36 \pm 25.28$ & 0.214 \\
\hline $\begin{array}{l}\text { Visit 5 } \\
\text { (1year) }\end{array}$ & $110.13 \pm 23.7$ & $131.7 \pm 30.55$ & $<0.001 * *$ \\
\hline$*$ p $<0.001$. & & & \\
\hline
\end{tabular}


Table 5 shows the changes in fasting blood glucose levels in study subjects. In group-I (risperidone) there was mean increase in fasting blood glucose levels from baseline $97.7 \pm 16.81$ to first follow up $105.27 \pm 20.54$ and in subsequent follow up it was increased to $110.13 \pm 23.7$. In group-II (olanzapine) there was mean increase fasting blood glucose in from baseline $97.9 \pm 18.45$ to first follow up $114.36 \pm 25.28$ and in subsequent follow up it was increased to $131.7 \pm 30.55$. There was statistically significant increase in fasting blood glucose from baseline to last follow up in both groups and it was significant when compared with each group.

\section{DISCUSSION}

The present observational comparative study on metabolic side effects of risperidone and olanzapine in the treatment of schizophrenia was conducted in Department of Psychiatry, Victoria hospital over a period of 1 year 6 months. The present study included a total of 60 patients. The mean age of study subjects was $37 \pm 9.60$ years. Among these patients $51 \%$ were males and $49 \%$ were females.

Weight gain has always been an issue with antipsychotics, but as a side effect it has historically been over shadowed by the risk of EPS. Atypical antipsychotics, as a class, carry a much lower risk of EPS but a much greater risk of weight gain. Olanzapine and clozapine seem particularly problematic in this respect. Mechanisms underlying this drug induced weight gain are not entirely clear; both the serotonin 5HT2C and the histamine H1 blocking activity of these drugs have been implicated. Patients with schizophrenia tend to have poor levels of nutrition, a $70 \%$ prevalence of smoking, and little or no preventative health care, so the cardiovascular risks associated with weight gain take on even greater importance. ${ }^{6-8}$ In this study both risperidone and olanzapine caused significant weight gain. But olanzapine caused more weight gain in comparison to risperidone. Earlier studies have demonstrated moderate weight gain with risperidone and significant weight gain with olanzapine. 9,10 The finding that olanzapine causes significant weight gain than risperidone found in the present study has been earlier reported by Lee et al and Conley et al. ${ }^{11,12}$ However, Basson et al observed that olanzapine and risperidone did not differ in their propensity to cause weight gain. ${ }^{13}$ In the present study both risperidone and olanzapine caused significant increase in body mass index by the end of treatment. Olanzapine caused significant increase in Body mass index when compared to risperidone. One year of treatment with Olanzapine and Risperidone was found to increase the BMI as per Rettenbacher et al. ${ }^{14}$ In the present study, waist hip ratio significantly increased after one year of treatment with risperidone and olanzapine. Olanzapine caused significant increase in waist to hip ratio as compared to risperidone. Obesity assessed by waist to hip ratio is a better predictor of cardiovascular disease and coronary heart disease mortality than waist circumference, which, in turn, is a better predictor than
BMI. The recognition of central obesity is clinically important, as lifestyle intervention is likely to provide significant health benefits. ${ }^{15}$ The study done by other investigators so far have not addressed the issue of waist hip ratio, during treatment with atypical antipsychotics.

Another related problem to weight gain is altered lipid profile. The underlying mechanisms are not clear, but the overall impairment of glucose levels seems to be consistent with insulin resistance. These changes could simply be secondary to weight gain, but the precise relationship is not clear, and there is the possibility that these lipid abnormalities are independent. ${ }^{6}$ In this study there was a significant increase in serum cholesterol, Serum triglyceride and serum LDL and decrease in serum HDL values with risperidone and with olanzapine treatment. Compared to risperidone, olanzapine induced significant increase in serum cholesterol, Serum triglyceride and serum LDL and decrease in serum HDL. This finding is in concurrence with the findings of many other earlier studies. ${ }^{16-18}$ Previous studies comparing the effect of the above drugs on lipid profile have also reported that olanzapine causes significant changes in lipid profile compared to risperidone. ${ }^{19,20}$ In our study there was statistically significant increase in fasting blood glucose level in risperidone group and olanzapine group. Olanzapine has caused significant increase in fasting blood glucose level when compared to risperidone. Similarly study by Ingole showed that the mean fasting blood sugar level was found to be significantly elevated after 6 and 12 weeks of treatment with olanzapine compared to risperidone. ${ }^{21}$ Contrarily study by Finkel showed that there was no significant difference in metabolic side effects like fasting blood sugar level of yearlong treatment with risperidone, olanzapine in comparison to treatment with haloperidol. ${ }^{1}$

The above changes like weight gain, glucose and lipid abnormalities are particularly worrisome because all these are independent risk factors for cardiovascular mortality. Regardless of aetiology, regular weight monitoring, glucose and lipid profile assessments are now advocated for patients receiving atypical antipsychotics.

There are few limitations of the study. The co-relation between dose of the drug and appearance of metabolic side effects were not taken into account. Study population $(n=30)$ is too small. Hence large studies are needed to confirm our study outcomes.

\section{CONCLUSION}

Apart from total cholesterol and triglycerides, metabolic side effects like increase in the weight, body mass index, waist hip ratio, fasting blood glucose, low density lipoproteins and decrease in high density lipoproteins were more among olanzapine treated patients than risperidone treated patients. In terms of metabolic side effects, risperidone is better than olanzapine. 


\section{ACKNOWLEDGEMENTS}

We are thankful to Dr. C.R. Jayanthi (professor and head, department of pharmacology, BMCRI), Dr. H. Chandrashekar (professor and head, department of psychiatry, Victoria hospital, Bangalore) for their kind support thought the study. We are also thankful to Dr. Rekha, Dr Manjula, for their continuous cooperation during present study.

Funding: No funding sources

Conflict of interest: None declared

Ethical approval: The study was approved by the Institutional Ethics Committee

\section{REFERENCES}

1. Finkel B, Goodman C, Melamed Y, Naser M, Andreyev P, Segev Y, et al. Difference in metabolic side effects of typical and atypical antipsychotic treatment in elderly individual with long term schizophrenia. Hong Kong J Psychiatr. 2009;19:1036.

2. Goeb JL, Marco S, Duhamel A, Kechid G, Bordet R, Thomas P, et al. Metabolic side effects of risperidone in early onset schizophrenia. Encephale. 2010;36(3):242-52.

3. Perez-Iglesias R, Crespo-Facorro B, Amado JA, Garcia-Unzueta MT, Ramirez-Bonilla ML, Gonzalez-Blanch C, et al. A 12-week randomized clinical trial to evaluate metabolic changes in drugnaive, first-episode psychosis patients treated with haloperidol, olanzapine, or risperidone. J Clin Psychiatr. 2007;68(11):1733-40.

4. Meyer JM. A retrospective comparison of weight, lipid, and glucose changes between risperidone and olanzapine treated inpatients:metabolic outcomes after 1year. J Clin Psychiatr. 2002;63:425-33.

5. Nuttall FQ. Body Mass Index: Obesity, BMI, and Health: A Critical Review. Nutr Today. 2015;50(3):117-28.

6. Kapur S, Remington G. Atypical Antipsychotics: New Directions and New Challenges in the Treatment of Schizophrenia. Ann Rev Med. 2001;52:503-17.

7. Allison DB, Mentor JL, Moonseong H, Chandler LP, Cappelleri JC, Infante MC, et al. AntipsychoticInduced Weight Gain. A Comprehensive Res Synthesis Am J Psychiatr. 1999;156:1686-96.

8. Basson BR, Kinon BJ, Taylor CC, Szymanski KA, Gilmore JA, Tollefson GD. Factors influencing acute weight change in patients with Schizophrenia treated with olanzapine, Haloperidol, or risperidone. J Clin Psychiatr. 2001;62(4):231-8.

9. Wetterling T. Body weight gain with atypical antipsychotics. A comparative review. Drug Safety. 2001;24(1):59-73.
10. Haddad P. Weight change with atypical antipsychotics in the treatment of Schizophrenia. J Psychopharmacol. 2005;19:16-27.

11. Lee E, Leung CM, Wong E. Atypical antipsychotics and weight gain in Chinese patients: A Comparison of olanzapine and risperidone. J Clin Psychiatr. 2004;65(6):864-6.

12. Conley RR, Mahmoud R. A Randomized DoubleBlind Study of Risperidone and Olanzapine in the Treatment of Schizophrenia or Schizoaffective Disorder. Am J Psychiatr. 2001;158:765-74.

13. Basson BR, Kinon BJ, Taylor CC, Szymanski KA, Gilmore JA, Tollefson GD. Factors influencing acute weight change in patients with Schizophrenia treated with olanzapine, Haloperidol, or risperidone. J Clin Psychiatr. 2001;62(4):231-8.

14. Rettenbacher MA, Ebenbichler C, Hofer A, Kemmler G, Baumgartner S, Edlinger M, et al. Early changes of plasma lipids during treatment with atypical antipsychotics. Int Clin Psychopharmacol. 2006;21(6):369-72.

15. Welborn TA, Dhaliwal SS and BennettSA. Waist-hip ratio is the dominant risk factor predicting cardiovascular death in Australia. Med J Australia. 2003; 179 (11/12):580-5.

16. Lindenmayer JP, Czobor P, Volavka J, Citrome L, Sheitman B, McEvoy JP, et al. Changes in Glucose and Cholesterol Levels in Patients With Schizophrenia Treated With Typical or Atypical Antipsychotics. Am J Psychiatr. 2003;160:290-6.

17. Nasrallah HA, Newcomer JW. Atypical antipsychotics and metabolic dysregulation: evaluating the risk/benefit equation and improving the standard of care. J Clin Psychopharmacol. 2004:7-14.

18. Eder IU, Ebenbichler C, Fleischhacker WW. Olanzapine-induced weight gain and disturbances of lipid and glucose metabolism. Essentials Psychopharmacol. 2005;6(2):112-7.

19. Del Valle MC, Loebel AD, Murray S, Yang R, Harrison DJ, Cuffel BJ. Change in Framingham Risk Score in Patients with Schizophrenia:A Post Hoc Analysis of a Randomized, Double-Blind, 6-Week Trial of Ziprasidone and Olanzapine. J Clin Psychiatr, Primary Care Companion. 2006;8:329-33.

20. Monteleone P, Martiadas V, Maj M. Management of schizophrenia with obesity, metabolic and endocrinological disorders. Psychiatr Clin N Am. 2009;32:775-94.

21. Ingole S, Belorkar NR, Waradkar P, Shrivastava M. Comparison of effects of olanzapine and risperidone on body mass index and sugar level in schizophrenic patients. Indian J Physiol Pharmacol. 2009;53(1):4754.

Cite this article as: Nagaraj L, Naveen KM. A comparative study of metabolic side effects of risperidone and olanzapine in the treatment of schizophrenia. Int J Basic Clin Pharmacol 2019;8:2561-5. 